Open access article, license CC BY-NC-ND

Issue IV, 22 November 2021

e-ISSN 2707-9481

Institute of Metallurgy and Ore Beneficiation, Satbayev University, Almaty, Kazakhstan

\author{
Mamaeva Aksaule Alipovna \\ JSC "Institute of Metallurgy and Ore Beneficiation" \\ Satbayev University Almaty, Kazakhstan \\ Email: a.mamayeva@satbayev.university \\ ORCID ID: 0000-0002-9659-8152 \\ Panichkin Aleksandr Vladimirovich \\ JSC "Institute of Metallurgy and Ore Beneficiation" \\ Satbayev University Almaty, Kazakhstan \\ Email: a.panichkin@satbayev.university \\ ORCID ID: 0000-0002-9659-8152
}

\author{
Kenzhegulov Aidar Karaulovich \\ JSC "Institute of Metallurgy and Ore Beneficiation" \\ Satbayev University Almaty, Kazakhstan \\ Email: a.kenzhegulov@satbayev.university \\ ORCID ID: 0000-0001-7001-2654 \\ Kshibekova Balzhan Bolatovna \\ JSC "Institute of Metallurgy and Ore Beneficiation" \\ Satbayev University Almaty, Kazakhstan \\ Email: b.kshibekova@satbayev.university \\ ORCID ID: 0000-0002-5944-7865
}

\title{
Deposition of a titanium carbonitride coating by magnetron sputtering on a substrate with a potential voltage
}

\begin{abstract}
Titanium carbonitride (TiCN) is of high relevance in the field of creating wear-resistant protective coatings in order to ensure maximum wear resistance and service life of parts of friction units. Titanium carbonitride coatings were obtained by magnetron sputtering at various bias substrate in the range from 0 to $-130 \mathrm{~V}$ with a step of $10 \mathrm{~V}$. The effect of the bias substrate on the deposition rate, phase and elemental composition, and the friction coefficient of the obtained coatings was investigated. As a result of the obtained dependences, the most optimal mode of deposition by the method of reactive magnetron sputtering with a negative bias voltage on the substrate was determined.
\end{abstract}

Keywords: titanium carbonitride, magnetron sputtering, bias substrate, coating, substrate.

Cite this article as: Mamaeva A.A.; Panichkin A.V.; Kenzhegulov A.K.; Kshibekova B.B. (2021). Deposition of a titanium carbonitride coating by magnetron sputtering on a substrate with a potential voltage. Challenges of Science. Issue IV, 2021, pp. 103-108. https://doi.org/10.31643/2021.16

\section{Introduction}

Today titanium carbonitride (TiCN) is of high relevance in the field of creating wear-resistant protective coatings in order to ensure maximum wear resistance and service life of parts of friction units. Due to its high resistance to abrasion and wear, TiCN is a more suitable coating for parts operating in constant friction $[1,2]$. TiCN coatings are formed by mixing $\mathrm{C}$ and $\mathrm{N}$ in an FCC structure and appear to have the best properties of the two precursors, such as the plasticity of TiC and the adhesion strength of TiN. It was found that the tribological properties of TiCN depend on the substrate, deposition method, film thickness, and structural features [3]. Therefore, the development of effective methods for obtaining coatings from TiCN in real industrial conditions is of great technological importance.

To date, various physical and chemical deposition technologies are used to obtain TiCN coatings. There are such methods as magnetron sputtering (MS) [4-6], cathode sputtering [7], plasma deposition [8], laser methods [9, 10], CVD-based methods $[11,12]$ and hybrid deposition $[13,14]$ and others. Among them, MS is one of the promising methods for the deposition of TiCN coatings with increased wear resistance. MS 
has a low level of impurities and makes it easy to control the deposition rate [15]. Depending on the spraying conditions, this method also allows one to obtain coatings with different morphologies and crystallographic structures. TiCN coatings exhibit a wide range of different properties depending on magnetron sputtering conditions, such as pressure and composition of the reactive gas, operating pressure, temperature, material and composition of the target, substrate, and others. Several studies of TiCN [5, 16-19] were carried out to study the effect of sputtering conditions on the properties of TiCN coatings, and the effect of bias voltage on the substrate has not been sufficiently clarified. In this regard, it is of interest to study the effect of the potential shift on the substrate on TiCN films obtained by the reactive MS method.

\section{Methods}

Titanium carbonitride (TiCN) coatings were deposited in a DC MS system using a titanium target. The target was prepared by cutting a titanium sheet of VT1-0 grade with a diameter of $99 \mathrm{~mm}$ and a thickness of $5 \mathrm{~mm}$. The distance between the target and the substrate holder was kept constant at $30 \mathrm{~cm}$. Well-polished steel plates of AISI 304, 40X and 10X18H10T grades, titanium and Al foil were used as substrates, which were acetone cleaned before being placed in the sputtering chamber. Before deposition, the chamber was evacuated to a base pressure below $510^{-5}$ Torr. The MS setup is equipped with an APEL-IS-21CELL ion source and APELMRE100 magnetrons. Before the deposition of coatings, the substrates were ionically cleaned with argon at an operating voltage of $2.5 \mathrm{kV}$, a current of $20-25 \mathrm{~mA}$, a pressure of $1-2.5 \cdot 10^{-3} \mathrm{Torr}$, with a duration of $20 \mathrm{~min}$. The testing of the modes of TiCN coating deposition was carried out under the conditions of asymmetric power supply of the magnetron sputtering system. For this, the potential voltage was applied not only to the magnetron, but also to the substrate. The substrate bias voltage $\left(U_{s}\right)$ was applied using an APEL-M-5PDC power supply. In order to study the effect of $U_{s}$ on the deposition rate (DP) and the composition of the displacement coating, the feed was applied from $0,-70,-90,-110,-120,-130 \mathrm{~V}$. The flow of inert and reaction gas was controlled by flow meters of the RRG12 brand. The total gas flow rate of $\mathrm{Ar} /$ $\mathrm{C}_{2} \mathrm{H}_{2}+\mathrm{N}_{2}$ was set at up to $1.5 \mathrm{~L} / \mathrm{h}$ to maintain the operating pressure in the chamber at $10^{-3}$ Torr. After reaching the working pressure of the $\mathrm{Ar} / \mathrm{C}_{2} \mathrm{H}_{2}+\mathrm{N}_{2}$ gas atmosphere, the plasma was ignited. The plasma current was recorded in all experiments at $2 \mathrm{~A}$, the voltage was varied in the range of 500-700 V. For this, an APEL-M-5PDC-1000A-1 power supply was used. The deposition time of all coatings is constant, 2 hours. Finally, the thickness of the TiCN films was in the range of $0.7-1.4 \mu \mathrm{m}$, which was checked using field emission scanning electron microscopy (SEM).

TiCN films were analyzed for morphology, elemental and phase composition. $\mathrm{CO}$ was defined as the ratio of the coating thickness to the deposition time. The thickness of the coatings was measured gravimetrically using a Sartorius Cubis MSA3.6P analytical balance and verified by scanning electron microscopy (SEM).

The morphology of the coatings was analyzed using SEM on a JXA-8230 (JEOL) microscope at an accelerating voltage of $20 \mathrm{kV}$ and an electron beam current of up to $7 \mathrm{nA}$. For all areas of the samples selected for SEM studies, the backscattered electrons (COMPO) mode was used. The elemental composition of the coating was determined by the method of energy dispersive $X$-ray analysis EDS.

The phase composition of the coating was determined using a D8 Advance (BRUKER) diffractometer with $\alpha$-Cu radiation $(\lambda \approx 1.54 \AA$ A $)$. $X$-ray photography was carried out with Bragg-Brentano focusing. Diffraction patterns were recorded in the range of angles $2 \theta: 20 \div 90^{\circ}$ with a step of $0.05^{\circ}$, the recording rate was 2 deg / min at a voltage of $35 \mathrm{kV}$ and a current of $20 \mathrm{~mA}$. For the phase analysis, the PDF 2 base was used.

The friction coefficient (CoF) of the coatings were measured in the sliding friction mode according to the "ball-on-disk" scheme on a TRB ${ }^{3}$ tribometer. Sample rotation speed $-1 \mathrm{~cm} / \mathrm{s}$, load $-1 \mathrm{~N}$, wear track radius - $4 \mathrm{~mm}$, friction path - $100 \mathrm{~m}$, data collection speed: $50 \mathrm{~Hz}$, a Si ${ }_{3} \mathrm{~N}_{4}$ ball with a diameter of $6 \mathrm{~mm}$ was used as a counter body.

\section{Results and discussion}

Figure 1 shows the dependence of DP and the TiCN film thickness on the negative bias voltage applied to the substrate. As can be seen from the graph, the thickness of the TiCN coating (Figure 1, black line) on the substrate without displacement is $1.45 \mu \mathrm{m}$, then it decreases to $0.78 \mu \mathrm{m}(-130 \mathrm{~V})$. The deposition rate 
(Figure 1, red line) decreases starting from the sample without substrate voltage to substrate bias $-130 \mathrm{~V}$ from 0.72 to $0.39 \mu \mathrm{m} / \mathrm{h}$, respectively. The reason for this is probably the effect of re-sputtering due to ion bombardment or surface growth by incoming ions, as noted in works [6, 20-23]. The negative bias voltage applied to the substrate provides continuous ion bombardment of the substrate. This is called re-sputtering, which reduces the DR of the TiCN coatings [6].

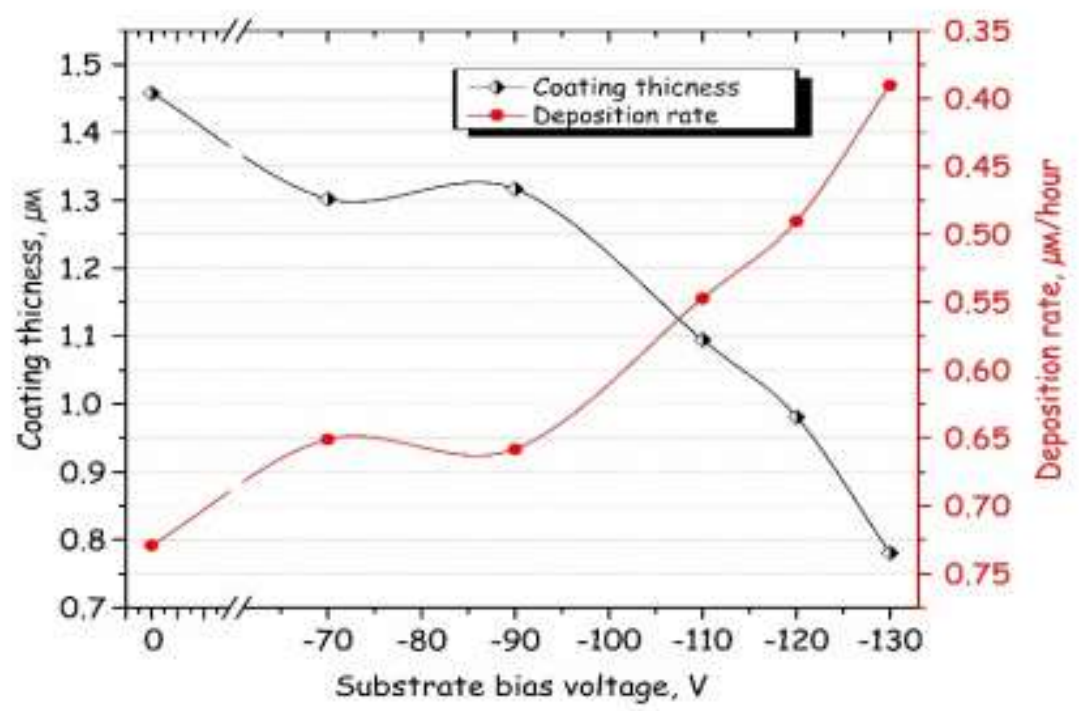

Figure 1. Dependence of the deposition rate and thickness of the TiCN coating on $\mathrm{U}_{s}$

The effect of the applied negative bias voltage on the chemical composition of TiCN coatings deposited at different $U_{s}$ is shown in Figure 2. The applied negative voltage noticeably affects the atomic composition of the coatings obtained. In the range $U_{s}$ from 0 to $-100 \mathrm{~V}$, the elemental composition of all coatings remains approximately constant. As the bias increases from $-100 \mathrm{~V}$, a significant change in the chemical composition is noted, namely, a decrease in the amount of nitrogen to 34 at.\% and an increase in carbon to 25.6 at.\%. Also, in this region of bias substrate, titanium increases slightly to 40.5 at.\%. The increase in the amount of carbon is apparently associated with the carburization of the surface of the titanium target with the prolongation of the deposition time, which creates favorable conditions in the plasma for the formation of TiC rather than TiN.

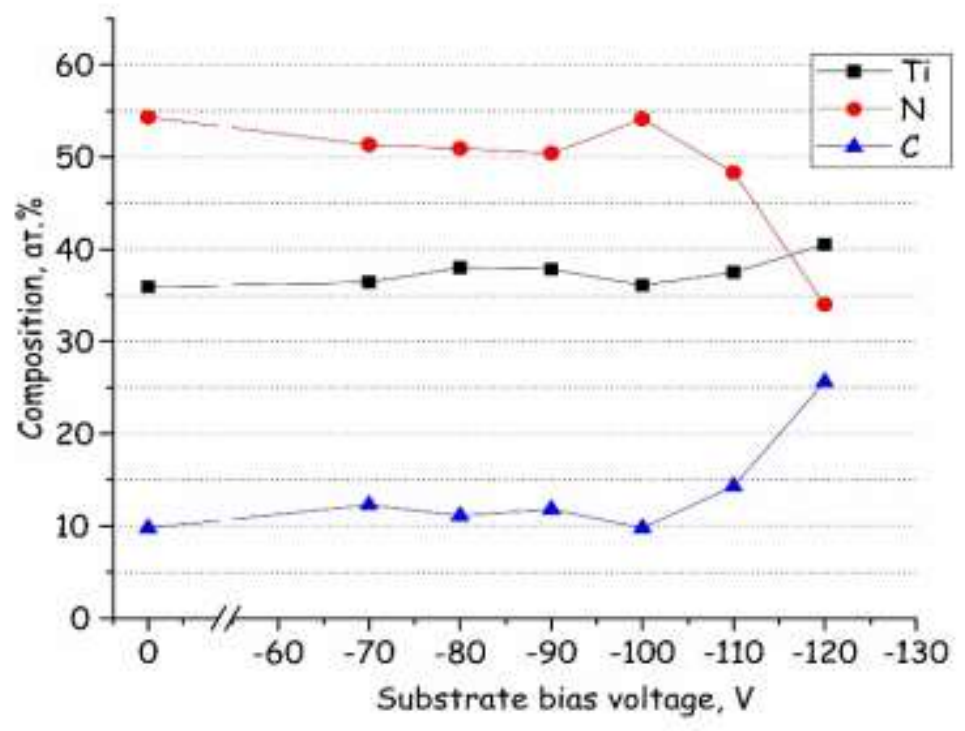

Figure 2. Dependence of the elemental composition of TiCN coatings on $U_{s}$ 
Substoichiometric concentration $\mathrm{Ti} /(\mathrm{C}+\mathrm{N})$ is one of the important ratios for $\mathrm{TiCN}$ coatings. The $\mathrm{Ti} /$ $(\mathrm{C}+\mathrm{N})$ ratio for the obtained coatings with and without substrate are shown in Table 1. In the coating applied without bias substrate, the ratio $\mathrm{Ti} /(\mathrm{C}+\mathrm{N})=0.56$ was observed. In the case of coatings with $\mathrm{U}_{\mathrm{s}}$, the substoichiometric concentration of $\mathrm{Ti} /(\mathrm{C}+\mathrm{N})$ is in the range from 0.58 to 0.68 . Among the deposited coatings, $-120 \mathrm{~V}$ has the closest substoichiometric concentration value, which is 0.68 . Although, it should be noted that in this sputterring mode of the MS coating is formed at a low deposition rate.

Table 1. The ratio of elements $\mathrm{Ti} /(\mathrm{C}+\mathrm{N})$ for the obtained TiCN coatings

\begin{tabular}{clllllll|}
\hline $\mathrm{U}_{\mathbf{s}}, \mathbf{V}$ & $\mathbf{0}$ & $\mathbf{- 7 0}$ & $\mathbf{- 8 0}$ & $\mathbf{- 9 0}$ & $\mathbf{- 1 0 0}$ & $\mathbf{- 1 1 0}$ & $\mathbf{- 1 2 0}$ \\
\hline $\mathrm{Ti} /(\mathbf{C}+\mathrm{N})$ & 0,56 & 0,58 & 0,61 & 0,61 & 0,56 & 0,59 & 0,68 \\
\hline
\end{tabular}

Figure 3 shows an X-ray phase analysis of TiCN coatings deposited at various negative substrate bias voltage. The diffraction patterns show that with an increase in the bias voltage of $0 \mathrm{~V}$ to $65 \mathrm{~V}$, the intensity of the diffraction maximum also increases, the content of acetylene in the composition of the reaction gas increases the lattice period of the coatings and the width of the X-ray line, decreases the texturing parameter of the coatings, but then, with a further increase to $-70 \mathrm{~V}$, the diffraction intensity decreases, and over time, with an increase to $-120 \mathrm{~V}$, remains stable.

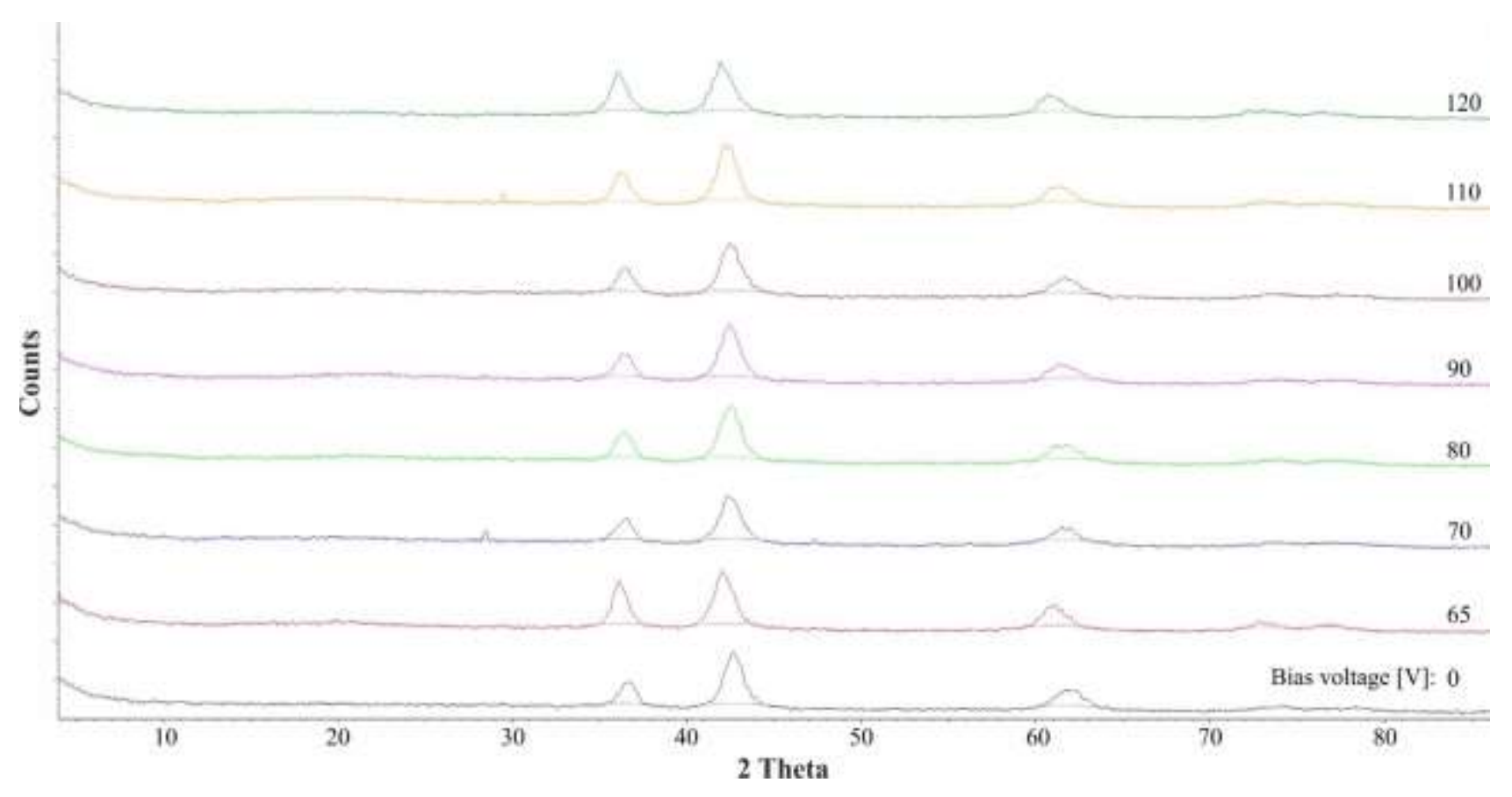

Figure 3. Influence of bias voltage during TiCN coating deposition on diffraction patterns

The wear resistance of TiCN coatings mainly depends on the microstructure, hardness and adhesion, which are usually measured in terms of the coefficient of friction and weight loss during wear [22]. Typically, TiCN coatings have a low coefficient of friction (CoF). The CoF of the deposited coatings at $U_{s}=0,-70,-100 \mathrm{~V}$ are shown in Figure 4. The resulting coatings showed an average CoF value from 0.06 to 0.188 . As can be seen, the low CoF has a sample deposited on the substrate with a potential bias of $-70 \mathrm{~V}$. In other cases, the CoF are approximately the same, which are in the region of about 0.18 . The CoF results are in good agreement with the results obtained for TiCN films by Saoula N. et al. [6, 22], however, the CoF for the $-70 \mathrm{~V}$ sample is much lower than in these works. The results show that it should be possible to obtain high wear resistance of the film with an appropriate choice of substrate bias. Currently, for these purposes, tribological and mechanical properties are being studied depending on the applied bias of the potential to the substrate during the deposition of TiCN coatings. 


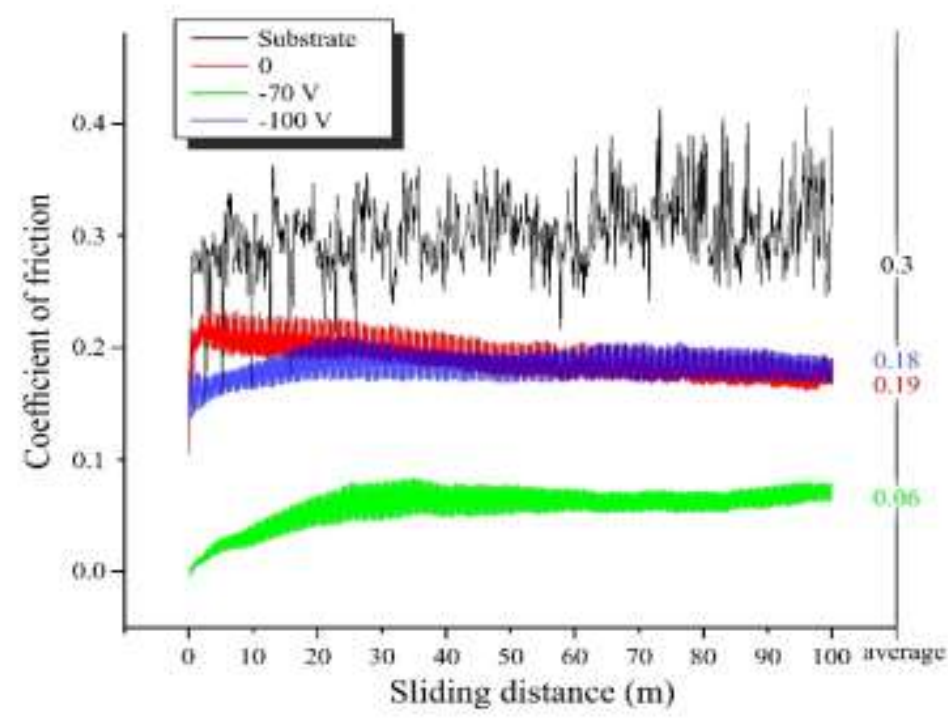

Figure 4. CoF for TiCN coatings obtained at $U_{s}=0,-70,-100 \mathrm{~V}$

\section{Conclusions}

In modern tribology, coatings made of titanium nitride - TiN and titanium carbonitride - TiCN are in the lead, since they have a lower cost and simplicity of production technology. TiCN coatings were deposited by magnetron sputtering on a substrate with displacement. The influence of the bias of the substrate potential on the deposition rate, elemental and phase composition of the coatings was investigated, and the coefficient of friction of the coatings was also studied. The deposition rate of the TiCN film decreases with increasing voltage on the substrate. With increasing stress, the concentration of titanium and carbon increases, along with a decrease in the concentration of nitrogen. A low coefficient of friction is recorded on TiCN coatings, obtained at - $70 \mathrm{~V}$. As a result, an optimal mode with a potential shift of $-70 \mathrm{~V}$ is determined, where TiCN coatings are formed with a low coefficient of friction and with a high deposition rate, with acceptable compositions. Further studies on tribological and mechanical tests are required to fully represent the quality of coatings for wear resistance, which will be determined at the next stage of the study.

\section{Acknowledgments}

This work was based on grant financing \# AP08857049 and supported by the Committee of Science of the Ministry of Education and Science of the Republic of Kazakhstan.

Cite this article as: Mamaeva A.A.; Panichkin A.V.; Kenzhegulov A.K.; Kshibekova B.B. (2021). Deposition of a titanium carbonitride coating by magnetron sputtering on a substrate with a potential voltage. Challenges of Science. Issue IV, 2021, pp. 103-108. https://doi.org/10.31643/2021.16

\section{References}

[1] Chen L., Wang S. Q., Zhou S. Z., Li J., Zhang Y.Z. Microstructure and mechanical properties of Ti(C,N) and TiN/Ti(C,N) multilayer PVD coatings // International Journal of Refractory Metals \& Hard Materials. 2008. Vol. 26. P. 456-460. doi:10.1016/j.ijrmhm.2007.10.003 (in Eng.).

[2] Ajikumar P. K., Kamruddin M., Kalavathi S., Balamurugan A. K., Kataria S., Shankar P., Tyagi A. K., Synthesis, characterization and evaluation of titanium carbonitride surface layers with varying concentrations of carbon and nitrogen // Ceramics International. 2012. Vol. 38. P. 2253-2259. doi: 10.1016/j.ceramint.2011.10.075 (in Eng.).

[3] Bull S., Bhat D., Staia M. Properties and performance of commercial TiCN coatings. Part 2: tribological performance // Surface and Coatings Technology. 2003. Vol. 163-164. P. 507-514. doi:10.1016/s0257-8972(02)00651-5 (in Eng.).

[4] Razmi, A.; Yesildal, R. Microstructure and mechanical properties of TiN/TiCN/TiC multilayer thin films deposited by magnetron sputtering // Preprints. 2018. 2018070127. doi: 10.20944/preprints201807. 0127.v1 (in Eng.). 
[5] Chen R., Tu J.P., et al. Microstructure, mechanical and tribological properties of TiCN nanocomposite films deposited by DC magnetron sputtering // Surface \& Coatings Technology. 2011. Vol. 205. P. 5228-5234. doi: 10.1016/j.surfcoat.2011.05.034(in Eng.).

[6] Saoula N., Madaoui N., Tadjine R., Erasmus R. M., Shrivastava S., Comins J.D. Influence of substrate bias on the structure and properties of TiCN films deposited by radio-frequency magnetron sputtering // Thin Solid Films. 2016. Vol. 616. P. 521-529. doi: 10.1016/j.tsf.2016.08.047 (in Eng.).

[7] Matei A. A., Pencea I., Stanciu S. G., Hristu R., Antoniac I., Ciovica (Coman) E., Sfat C.E., Stanciu G.A. Structural characterization and adhesion appraisal of TiN and TiCN coatings deposited by CAE-PVD technique on a new carbide composite cutting tool // Journal of Adhesion Science and Technology 2015. Vol. 29. P. 2576-2589. doi: 10.1080/01694243.2015.1075857 (in Eng.).

[8] Zhu L., He J., Yan D., Liao H., Zhang N. Oxidation Behavior of Titanium Carbonitride Coating Deposited by Atmospheric Plasma Spray Synthesis. Journal of Thermal Spray Technology 2017. Vol. 26. N. 7. P. 1701-1707. doi:10.1007/s11666-017-0620-z (in Eng.).

[9] Yang Y., Guo N., Li J. Synthesizing, microstructure and microhardness distribution of Ti-Si-C-N/TiCN composite coating on Ti-6Al-4V by laser cladding // Surface and Coatings Technology. 2013. Vol. 219. Vol. 12. P. 1-7. doi: 10.1016/j.surfcoat.2012.12.038 (in Eng.).

[10] Yang Y.L., Yao W.M., Zhang H.Z. Phase constituents and mechanical properties of laser in-situ synthesized TiCN/TiN composite coating on Ti-6Al-4V // Surf. Coat. Technol. 2010. Vol. 205. P. 620-624. doi: 10.1016/j.surfcoat.2010.07.058 (in Eng.).

[11] Zhang J., Xue Q., Li S. Microstructure and corrosion behavior of TiC/Ti(CN)/TiN multilayer CVD coatings on high strength steels // Applied Surface Science. 2013. Vol. 280. P. 626-631. doi: 10.1016/j.apsusc.2013.05.037 (in Eng.).

[12] Fang T.H., Jian S.R., Chuu D.S. Nanomechanical properties of TiC, TiN and TiCN thin films using scanning probe microscopy and nanoindentation // Applied Surface Science. 2004. Vol. 228(1-4). P. 365-372. doi:10.1016/j.apsusc.2004.01.053 (in Eng.).

[13] Restello S., Boscarino D., Rigato V. A study of $\mathrm{Ti}-\mathrm{C}-\mathrm{N}(\mathrm{H})$ and $\mathrm{Ti}: \mathrm{CNx}(\mathrm{H})$ coatings grown with a magnetron sputtering/PECVD hybrid deposition process // Surface and Coatings Technology. 2006. Vol. 200(22-23). P. 6230-6234. doi: 10.1016/j.surfcoat.2005.11.029 (in Eng.).

[14] Tillmann W., Grisales D., Tovar C.M., Contreras E.; Apel D., Nienhaus A., Stangier D., Lopes D.N.F. Tribological behaviour of low carbon-containing TiAICN coatings deposited by hybrid (DCMS/HiPIMS) technique // Tribology International. 2020. Vol. 151. 106528. doi: 10.1016/j.triboint.2020.106528 (in Eng.).

[15] Auciello O., Engemann J. Multicomponent and Multilayered Thin Films for Advanced Microtechnologies: Techniques, Fundamentals and Devices, NATO ASI Series, 1993. Vol. 234. Springer ISBN: 978-94-011-1727-2 (in Eng.).

[16] Polcar T. R., Novak P., Siroky P. The tribological characteristics of TiCN coating at elevated temperatures // Wear. 2006. Vol. 260. P. 40-49. doi:10.1016/j.wear.2004.12.031 (in Eng.).

[17] Zheng X.H., Tu J.P., Gu B., Hu S.B. Preparation and tribological behavior of TiN/a-C composite films deposited by DC magnetron sputtering // Wear. 2008. Vol. 26. P. 261-265. doi:10.1016/j.wear.2007.10.007 (in Eng.).

[18] Hsieh J.H., Wu W., Li C., Yu C.H., Tan B.H. Deposition and characterization of $\mathrm{Ti}(\mathrm{C}, \mathrm{N}, \mathrm{O})$ coatings by unbalanced magnetron sputtering // Surface and Coatings Technology. 2003. Vol. 163. P. 233-237. doi:10.1016/s0257-8972(02)00494-2 (in Eng.).

[19] Correa J.F., Aperador W., Caicedo J.C., Alba N.C., Amaya C. Structural, mechanical and tribological behavior of TiCN, CrAIN and BCN coatings in lubricated and nonlubricated environments in manufactured devices // Materials Chemistry and Physics. 2020. Vol. 252. P. 123164. doi:10.1016/j.matchemphys.2020.123164. (in Eng.).

[20] Wang H., Zhang S., Li Y., Sun D. Bias effect on microstructure and mechanical properties of magnetron sputtered nanocrystalline titanium carbide thin films // Thin Solid Films. 2008. Vol. 516. P. 5419-5423 (in Eng.).

[21] Panichkin A.V., Kenzhaliyev B.K., Kenzhegulov A.K., Imbarova A.T., Karboz Zh.A., Shah A. The effect of the catalytic layer composition on the hydrogen permeability of assymetric tantalum-based membranes. Kompleksnoe Ispol'zovanie Mineral'nogo Syr'a = Complex Use of Mineral Resources. 2020. № 4 (315), pp. 82-95. https://doi.org/10.31643/2020/6445.40 (in Eng.).

[22] Wang Z., Zhang D., Ke P., Liu X., Wang A. Influence of substrate negative bias on structure and properties of TiN coatings prepared by hybrid HIPIMS method // Mater. Sci. and Technol. 2015. Vol 31(1). P. 37- 42. (in Eng.).

[23] Mechri H., Saoula N., Madaoui N. Friction and wear behaviors of TiCN coating treated by R.F magnetron sputtering / / 7th African Conference on Non Destructive Testing ACNDT \& the 5th International Conference on NDT and Materials Industry and Alloys (IC-WNDT-MI). - Algiers, Algeria. -2016, p. 1-4. (in Eng.). 